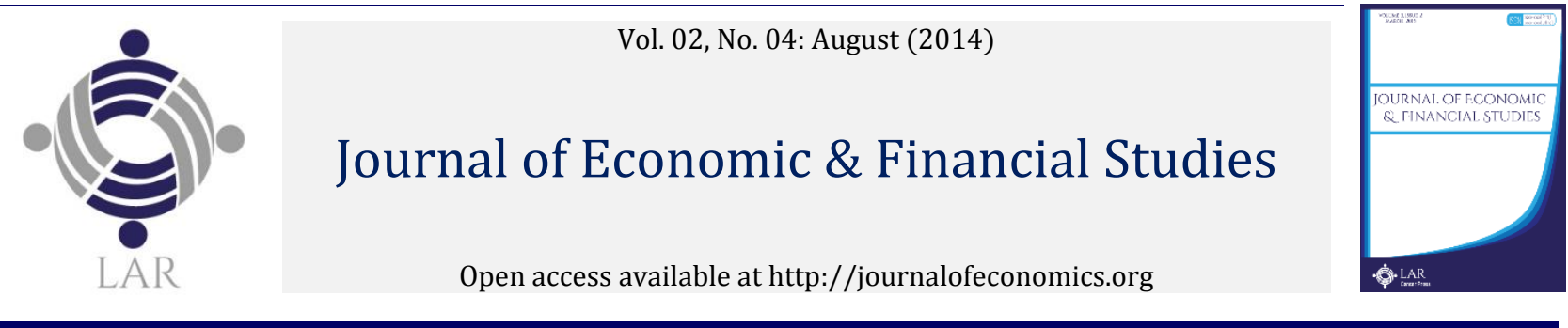

\title{
An empirical analysis on credit risk model and its application
}

\author{
Joocheol Kimª , Eunhwan Kim ${ }^{\mathrm{b}}$ \\ a School of Economics, Yonsei University, Korea. \\ b School of Economics, Yonsei University, The Korea Development Bank (KDB), Korea. \\ *Corresponding author's e-mail: joocheol@yonsei.ac.kr
}

\section{H I G H L I G H T S:}

1. Owing to various complexity and validity of model estimation, various credit risk models fail to provide a standard credit risk measurement for the market participants.

2. Most market participants utilize ratings of target firm in measuring credit risk. However, credit ratings have only so many grades that credit ratings do not deliver precise credit risk measure.

3. Inter-bank derivatives transactions in OTC market require credit support to mitigate counterparty's default risk. Threshold level of a bank is determined solely according to its corresponding global credit rating.

4. We suggest standardizing credit risk measurement with distance-to-default value inferred from equity market value and volatility adopted from KMV model, and then applying the outcome to credit support calculation to efficiently allocate resources.

\section{Article History}

Received:02-07-2014

Accepted: 05-08-2014

Available online: 07-08-2014

\section{Keywords:}

Collateral management;

Expected default frequency; KMV.

\section{ABSTRACT}

This study intends to focus on introducing credit default risk with widely used credit risk models in an effort to empirically test whether the models hold their validity, apply to financial institutions which usually are highly levered with various types of debts, and finally reinterpret the results in computing adequate collateral level in the over-the-counter derivatives market. By calculating the distance-to-default values using historical market data for South Korean banks and brokerage firms as suggested in Merton model and KMV's EDF model, we find that the performance of the introduced models well reflect the credit quality of the sampled financial institutions. Moreover, we suggest that in addition to the given credit ratings of different financial institutions, their distance-to-default values can be utilized in determining the sufficient level of credit support. Our suggested "smoothened" collateral level allows both contractual parties to minimize their costs caused from provision of collateral without undertaking additional credit risk and achieve efficient collateral management.

JEL Classification: C53; G17; G20. DOI: http://dx.doi.org/10.18533/jefs.v2i03.78

(C) 2014 The Authors. This is an open access article under the terms of the Creative Commons Attribution License 4.0, which allows use, distribution and reproduction in any medium, provided the original work is properly cited.

\subsection{Introduction}

Banks measure credit risk of borrowers not only to price their loans but also to diversify portfolio as well as to determine their credit qualities. Among the various risk factors such as market risk or operational risk, credit default risk requires closer attention because the extent of the loss given default is considerably larger despite default is a rare event with lower odds. All Banks regardless of their geographic regions internally allocate majority of their resources to manage credit risk and build models to anticipate future possible event of default. Expansion of use of credit requires forward looking measure to all financial institutions whose products or services mismatch their payment time. 
Inter-bank credit risk arises from the counterparties' default possibility in over-the-counter derivatives trades and transactions. All have witnessed in the year of 2008 that default of financial institutions is not an uncommon event. Collapse of financial institutions like Bear Sterns or Lehman Brothers and its contagion can easily cause irrevocable and instantaneous harm to the other side of transaction counterparties and consequently banks emphasize the importance of credit support or collateral requirement to reduce their open exposure to a certain threshold level. Inter-bank traders often reflect credit risk to quoted prices (for example interest rate swap) unless above mentioned credit support is pledged and provided. The provision of collateral then leads to banks' opportunity cost loss and hence determining the adequate level of collateral in legal agreement (e.g. ISDA CSA ${ }^{1}$ ) would be critical.

Most previous empirical studies on EDF model (Expected Default Frequency) have dealt with various industries ranging from manufacturing to pharmaceutical listed companies in the stock exchange but direct credit risk measure on financial institutions was rarely introduced. This is mostly because financial institutions, especially banks, are the ones who are exposed to credit risk of counterparties and in needs of credit risk protection, not the other way around. Another possible reason is that financial institutions are on a blurring line between private and public sectors ${ }^{2}$ for which credit risk could be considered low from the historical point of view. However, exposure accumulated by inter-bank derivatives transactions would be simply larger than any other exposure from loans or investment on firms and consequently, credit measure on financial institutions is no less important. In this study, Merton model and Expected Default Frequency model developed by Moody's KMV will be introduced in order to discover further that the models are acceptable in measuring credit risk of financial institutions. Financial institutions often utilize credit support to mitigate the counterparty risk but the collateral threshold method currently adopted by most financial institutions results in inefficient allocation of bank resource. This study will suggest alternative threshold standard level using the prevailing option pricing model.

The idea of collateral management was developed in the 1980's and became widespread in the 1990's as OTC derivatives trades exploded. Estimated value of total collateral grew from USD 200 billion in 1999 to USD 3,151 billion in $2009^{3}$ and types of assets used as collateral consist of 82 percent of cash and 14.2 percent of government securities. Cash collateral provision typically causes financial institutions a loss of opportunity cost and the increase of collateral provision threatens profitability of financial institutions. Most previous studies on collateral management often focus on the operational risk as margin calls occur daily between the counterparties or on lending and borrowing programs like repo transactions. Another common study field is to quantify credit valuation adjustment and debt valuation adjustment which directly reflect counterparty's credit risk in the quoted prices regarding OTC derivatives transactions. Although it is true that market convention and practice is heavily immersed and pervaded in collateral management, we intend to directly challenge it and offer more efficient fundamental change to collateral management by calculating more precise credit risk level so neither party would provide excess collateral amount.

\subsection{Credit risk models}

Credit risk is the risk of decline in the credit quality of counterparty in financial transactions and trades, and the core source of credit risk is the default risk that the counterparty may not fulfill its contractual obligations. There are two main streams of modeling credit risk; 1) structural approach and 2) reduced form approach. The following part will introduce few of the renowned models that intuitively measure credit default risk.

\subsection{Merton's model ${ }^{4}$}

Merton (1974) applied options models to evaluate the credit risk of a firm's debt. This classic model explicitly generates the probability of default at a certain point of time. In order to calculate the default probability, the framework of Merton indicates that the equity of a firm is considered as a call option on the underlying asset value of the firm with a strike at the value of the firm's liabilities. The underlying value of a firm and its volatility are not directly observed from the model and it assumes that the both values are inferred from the market value of equity, volatility of equity and other known variables by solving two non-linear equations which will be discussed further in this study. The inferred values then can be applied to find the probability of default which is the normal cumulative density function of $z$-value.

\subsubsection{Assumptions}

Merton's model assumes that (1) a firm only issues a single discount zero coupon bonds with a face value of $K$ and maturity at $T$ for its debt financing. At maturity if the asset value of the firm (firm value) exceeds its book value of

\footnotetext{
1 ISDA: International Swaps and Derivatives Association, Inc. CSA: Credit Support Annex

${ }^{2}$ Financial institutions are often "Too big to fail".

${ }^{3}$ ISDA Margin Survey, 2010.

${ }^{4}$ Merton, R., 1974, On the Pricing of Corporate Debt: The Risk Structure of Interest Rates, Journal of Finance, Vol. 29, No. 2, 449-470.
} 
liabilities $(K)$, shareholders would pay off its debt $(K)$ and the firm will continue to exist. On the other hand, if the firm value is less than the redemption amount at maturity then shareholders would file for bankruptcy. The model assumes (2) there is an absence of transaction costs regarding the default event which include bankruptcy costs, taxes or any other relevant cost issues and each of the debt holders has the priority over shareholders. In this case of default, the value of the equity becomes 0 . Merton's model assumes (3) constant risk free rate and volatility. The total value of a firm is then assumed to follow geometric Brownian motion,

$\left.d V_{t}=\mu V_{t} d t+\sigma V_{t} d W_{t}\right)$

where,

$V$ is the total value of the firm,

$\mu$ is the expected continuously compounded return on $V($ i.e., the asset drift),

$\sigma$ is the volatility of firm value and $d W$ is a standard Weiner process.

By definition the value of the firm following geometric Brownian motion indicates $V_{t}$ is normal and lognormally distributed. The value of the firm's asset at time $t$ is given by the following stochastic differential equation,

$\left.V_{t}=V_{0} \exp \left[\left(\mu-\frac{\sigma^{2}}{2}\right) t+\sigma W_{t}\right]\right)$

\subsubsection{Modeling5}

In this model, default occurs when $V_{t}$ falls beyond the value of the issued discount zero coupon bond $(K)$ at time $t$. This can be reinterpreted as an option with underlying asset of the value of the firm and strike price at its face value of the bond. In another word, holding the firm's bond equals to taking a long position of risk free asset and a short position of put option with strike price $K$. The equity of the firm is then a vanilla European call option on the assets of the firm with maturity $T$ and a strike price equal to the face value of the debt.

\begin{tabular}{lccc}
\hline \multicolumn{4}{c}{ Table 01: Merton's model and payoffs for equity and bond holders } \\
\hline & Default $\left(V_{t}<K\right)$ & Non-Default $\left(V_{t}>K\right)$ & Payoff \\
\hline Equity & 0 & $V_{t}-K$ & $\max \left[V_{t}-K, 0\right]$ \\
Bond & $V_{t}$ & $K$ & $K-\max \left[V_{t}-K, 0\right]$ \\
\hline
\end{tabular}

Merton adopts option pricing model to derive the value of firm given by

$v(t, T)=F(t, T)-P(t) \quad$..............Eq. (03)

Where,

$v(t, T)$ is the present value of discount bond with maturity $T$ at time $t$

$F(t, T)$ is the present value of riskfree discount bond with face value of $K$ at time $t$

$P(t)$ is the present value of a European put option with strike at $K$ at time $t$.

Equation (03) shows the value of the corporate bond is given by subtracting the value of a European put option with underlying asset of $V_{t}$ from the value of risk free discount bond with $K$. Since the value of risk free discount bond is determined, the value of the firm's bond then depends on the value of the put option. In Merton's model, risk free rate is given as constant and hence the value of put option can be drawn from Black and Scholes option pricing model ${ }^{6}$.

$P(t)=\left[-V(t) \frac{N\left(-d_{1}\right)}{N\left(-d_{2}\right)}+F(t, T)\right] N\left(-d_{2}\right)$

where,

$d_{1}=\frac{\ln \left(\frac{V_{t}}{K}\right)+\left(r+\frac{1}{2} \sigma^{2}\right)(T-t)}{\sigma \sqrt{T-t}}$

$d_{2}=d_{1}-\sigma \sqrt{T-t}$

${ }^{5}$ Replication of Merton's model is referred from various text books which includes;

Hull, J., 2002, Options, Futures, and Other Derivatives, Fifth Edition, Prentice Hall.

Caouette, J., Altman, E., Narayanan, P., Nimmo, R., 2008, Managing Credit Risk: The Great Challenge for the Global Financial Markets, Second Edition, John Wiley \& Sons, Inc.

Jo, H., 2003, Credit Risk: Measurement and Management, Segyeong.

${ }^{6}$ Put option pricing equation: $P(t)=-S(t) N\left(-d_{1}\right)+K e^{-r(T-t)} N\left(-d_{2}\right)$ 
Equation (04) indicates that $\left[-V(t) \frac{N\left(-d_{1}\right)}{N\left(-d_{2}\right)}+F(t, T)\right]$ is the expected loss given default and multiplying it with $N\left(-d_{2}\right)$ becomes the expected loss (EL). Therefore, plugging in the value of put option derived from equation (04) into equation (03), we can retrieve the following

$v(t, T)=F(t, T)+V(t) N\left(-d_{2}\right) \quad \ldots \ldots . . \quad$ Eq. $(05)$

where the $F(t, T)$ is the value of the firm's discount bond without an event of default and $V(t) N\left(-d_{2}\right)$ is the value of the firm's discount bond with an event of default. In the Merton framework, the value of the firm's bond is determined by the difference between the values of its asset and liability, leverage ratio, maturity and asset volatility.

\subsubsection{Default probability}

The value of asset, $V_{t}$, follows a path of geometric Brownian motion and subsequently the default probability can be drawn as

$$
\begin{aligned}
& \operatorname{Pr}\left(V_{T}<K\right)=\operatorname{Pr}\left[V_{t} \exp \left(\mu-\frac{\sigma^{2}}{2}\right)(T-t)+\sigma W(T-t)<K\right] \\
& =\operatorname{Pr}\left[W(T-t)<\frac{\ln \left(\frac{K}{V_{t}}\right)-\left(\mu-\frac{\sigma^{2}}{2}\right)(T-t)}{\sigma}\right] \ldots \ldots \ldots \ldots . . . \text { Eq. (06) }
\end{aligned}
$$

The standard Brownian motion $W(T-t)$ follows a normal distribution with its mean value of zero and variance with $(T-t)$, and can be reiterated as the below cumulative density function,

$\operatorname{Pr}\left(V_{T}<K\right)=N\left[\frac{\ln \left(\frac{K}{V_{t}}\right)-\left(\mu-\frac{\sigma^{2}}{2}\right)(T-t)}{\sigma \sqrt{T-t}}\right]$

where $^{7} W(T-t)=Z(T-t)$ and hence the equivalent martingale measure is

$$
\begin{aligned}
& \operatorname{Pr}\left(V_{T}<K\right)=N\left(-d_{2}\right)=1-N\left(d_{2}\right) \\
& 2.2 \quad \text { Moody's EDF }{ }^{\mathrm{TM}} \text { (Expected default frequency) }
\end{aligned}
$$

The EDF Model ${ }^{8}$ was developed by the KMV Corporation in the early 1990's then implemented further by Moody's in 2002. The model adopted Black-Scholes option pricing model and previously introduced Merton's Model to generate the default probability of a firm. Measuring default probability requires the following three steps:

1) Estimate asset value and asset volatility

2) Find the value of distance-to-default(DD)

3) Find the default probability

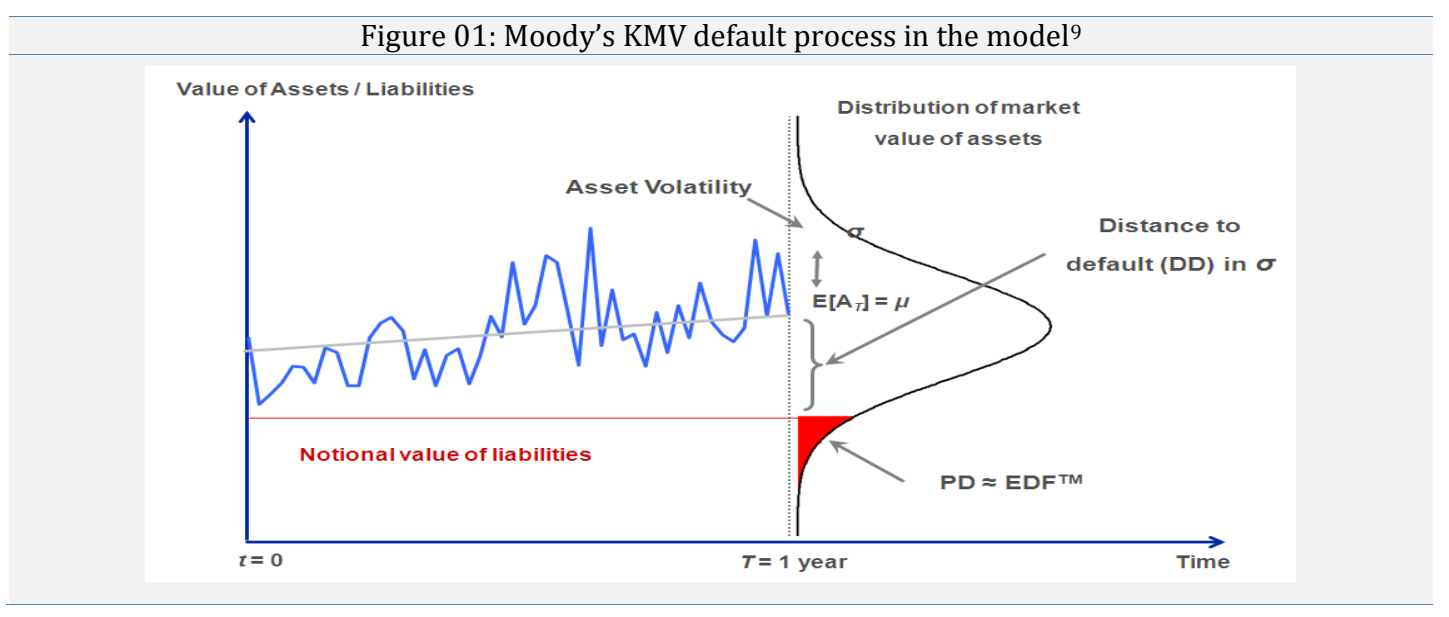

\footnotetext{
${ }^{7} \mathrm{Z}$ is standard normal distribution with $\mu=0$ and $\sigma^{2}=1$

${ }^{8}$ The model is now provided to subscribers of Moody's.

${ }^{9}$ Default process Figure from Munves, D., Smith, A., Hamilton, D., 2010, Banks and their EDF Measures Now and Through the Credit Crisis: Too High, Too Low, or Just About Right?
} 


\subsubsection{Estimate asset value and asset volatility}

For a publicly traded company, the asset value and volatility can be estimated from the market price and volatility of equity and the book value of liabilities using options pricing approach which recognizes equity as a call option on the underlying assets of the firm. Suppose a firm with a single class of debt and equity. The equity holder now possesses the right to pay off the debt holder and take over the remaining assets of the firm. In this case, equity is simply a call option on the firm's assets with its strike equal to the book value of liabilities. In practice by solving two equations ${ }^{10}$ with two unknowns, the asset value and volatility, we can determine as shown below; (08) and (09).

$\left[\begin{array}{c}\text { Equity } \\ \text { Value }\end{array}\right]=$ OptionFunction $\left(\left[\begin{array}{c}\text { Asset } \\ \text { Value }\end{array}\right],\left[\begin{array}{c}\text { Asset } \\ \text { Volatility }\end{array}\right],\left[\begin{array}{c}\text { Capital } \\ \text { Structure }\end{array}\right],\left[\begin{array}{c}\text { Interest } \\ \text { Rate }\end{array}\right]\right)$

$\left[\begin{array}{c}\text { Equity } \\ \text { Volatility }\end{array}\right]=$ OptionFunction $\left(\left[\begin{array}{c}\text { Asset } \\ \text { Value }\end{array}\right],\left[\begin{array}{c}\text { Asset } \\ \text { Volatility }\end{array}\right],\left[\begin{array}{c}\text { Capital } \\ \text { Structure }\end{array}\right],\left[\begin{array}{c}\text { Interest } \\ \text { Rate }\end{array}\right]\right)$

The value of underlying assets follows the following stochastic process.

$d V_{A}=\mu V_{A} d t+\sigma_{A} V_{A} d z$ Eq. (10)

where, $V_{A}$ and $d V_{A}$ are asset value and change in asset value, respectively. $\mu$ and $\sigma_{A}$ are asset value drift rate and volatility. $d z$ is simply a standard Wiener process. If $K$ is the book value of the debt due at time $t$, then the market value of equity and the market value of assets are related as the following expression;

$V_{E}=V_{A} N\left(d_{1}\right)-e^{-r(T-t)} K N\left(d_{2}\right)$ Eq. (11)

$V_{E}$ is the market value of the equity and, $d_{1}$ and $d_{2}$ represent the following equations. $r$ here is the risk free interest rate.

$d_{1}=\frac{\ln \left(\frac{V_{A}}{K}\right)+\left(r+\frac{1}{2}{\sigma_{A}}^{2}\right)(T-t)}{\sigma_{A} \sqrt{(T-t)}}$

$d_{2}=d_{1}-\sigma_{A} \sqrt{(T-t)}$

It follows directly from Ito's lemma that the equity volatility and asset volatility are related as the following expression;

$\sigma_{E}=\left(\frac{V_{A}}{V_{E}}\right)\left(\frac{\partial V_{E}}{\partial V_{A}}\right) \sigma_{A}$

The asset value and volatility implied by the book value of the liabilities, the equity value and volatility are determined by "solving"11 the call price and volatility equations, (11) and (12) simultaneously.

\subsubsection{Find the value of distance-to-default (DD)}

Once the asset value and volatility are inferred numerically from the two equations, the distance to default can be calculated simply as

$D D=\frac{\ln \left(\frac{V_{A}}{K}\right)+\left(\mu-\frac{1}{2} \sigma_{A}^{2}\right)(T-t)}{\sigma_{A} \sqrt{(T-t)}}$

where, $\mu$ is an estimate of the expected annual return of the firm's assets. This is nothing but $N\left(d_{2}\right)^{12}$ in the BlackScholes model ${ }^{13}$.

\subsubsection{Find the default probability}

In this study, Normal Distribution is assumed to calculate a firm's distance-to-default and its default probability which is expressed as

\footnotetext{
${ }^{10}$ Crosbie, P., Bohn, J., 2003, Modeling Default Risk.

${ }^{11}$ Solver, Mathematical software terminology, provides solution finding for nonlinear equations.

${ }_{12}$ The difference is that DD uses return of assets, $\mu$, whereas $d_{2}$ uses risk free interest rate, $r$.

${ }^{13} N\left(d_{2}\right)=\operatorname{Pr}\left(V_{A}>K\right)$
} 
Expected Default Frequency $=N\left(-\frac{\ln \left(\frac{V_{A}}{K}\right)+\left(\mu-\frac{1}{2} \sigma_{A}^{2}\right)(T-t)}{\sigma_{A} \sqrt{(T-t)}}\right) \ldots \ldots \ldots \ldots \ldots . .$. Eq. (14)

But KMV suggests a relationship between distance-to-default and default probability from historical bankruptcy frequencies ${ }^{14}$.

\subsubsection{Model evaluation}

The most significant feature of the KMV's EDF model would be that the model utilizes market value of equity to estimate the firm's asset value. In other words, the model contains future-oriented and forward looking measures functioning as an early warning system because the default probability is derived from option pricing model with equity value which reflects firm's future expected performance at a given time horizon.

\subsection{Empirical testing}

Financial institutions, especially banks, encounter a performance reliance issue in measuring banks' EDF values because the EDF values are seldom too high or too low in an absolute term according to the subscribers of KMV model as well as Moody's Analytics ${ }^{15}$. This study will tackle such a discrepancy by assessing the level of default risk of each bank using historical financial data and equity market data. The absolute EDF value which does not fully convey the inherent default risk will be replaced with simple $d_{2}$ value, distance-to-default value. Then, the acquired values will be observed in line with the movement and momentum of the calculated distance-to-default values in a given time period. The empirical test will be conducted in the following manner: (1) assumptions, (2) distance-todefault movement of defaulted banks, (3) distance-to-default movement of survived banks, and (4) reflection of historical economic impact.

The test results are expected to include (1) valid early signal of EDF values (distance-to-default value in this study as a proxy for EDF value) for South Korean banks and (2) reflection of external economic impact during the test period.

\subsection{Test assumption}

For this study, 39 data sets of historically delisted banks from South Korean stock exchange and 9 data sets of currently listed banks are retrieved within the period from year 2000 up to year 2013. All sample data were tested to calculate the value of Distance-to-Default. Comparisons are strictly conducted with their Distance-to-Default level movement. All calculations are performed based on the theoretical calculation method introduced EDF model earlier in the study that is to calculate the value of $d_{2}$. KTB 1year yield ${ }^{16}$ is used as a proxy for risk-free interest rate. Some of the banks only survived short periods within the test years and some of the banks were restructured during the test period. Although we have tested all possible banks that have been listed in the exchange, not all samples showed consistent results due to the above reasons. Also, in this study we eliminate all sudden effect of financial statement (except capital increase or decrease) or any other business impact which could harm the purpose of the study. Nonetheless, the momentum of their movement of Distance-to-Default should suggest significant results. The vertical axis represents distance-to-default and the horizontal axis is the time period in the following figures.

\subsection{Distance to default movement of defaulted banks}

The values of distance-to-default between year 2006 and year 2012 were calculated for those banks which eventually filed for bankruptcy and delisted. 6 banks, all savings banks, were chosen from the sample data and the banks were divided into two groups, ratings above and below BBB; then one from each sample group was chosen to show the level movement of distance-to-default.

\footnotetext{
${ }^{14}$ Historical data of over 250,000 companies and over 4,700 incidents of default or bankruptcy provides fatter tailed distribution and the default probability, therefore, shows higher value than normal distribution.

${ }^{15}$ Moody's Analytics is a subsidiary of Moody's Corporation

${ }^{16}$ Korea Treasury Bond 1 year yields match well in this model compared to commonly used CD 91 day, KTB 3yr and inter-bank overnight rate.
} 


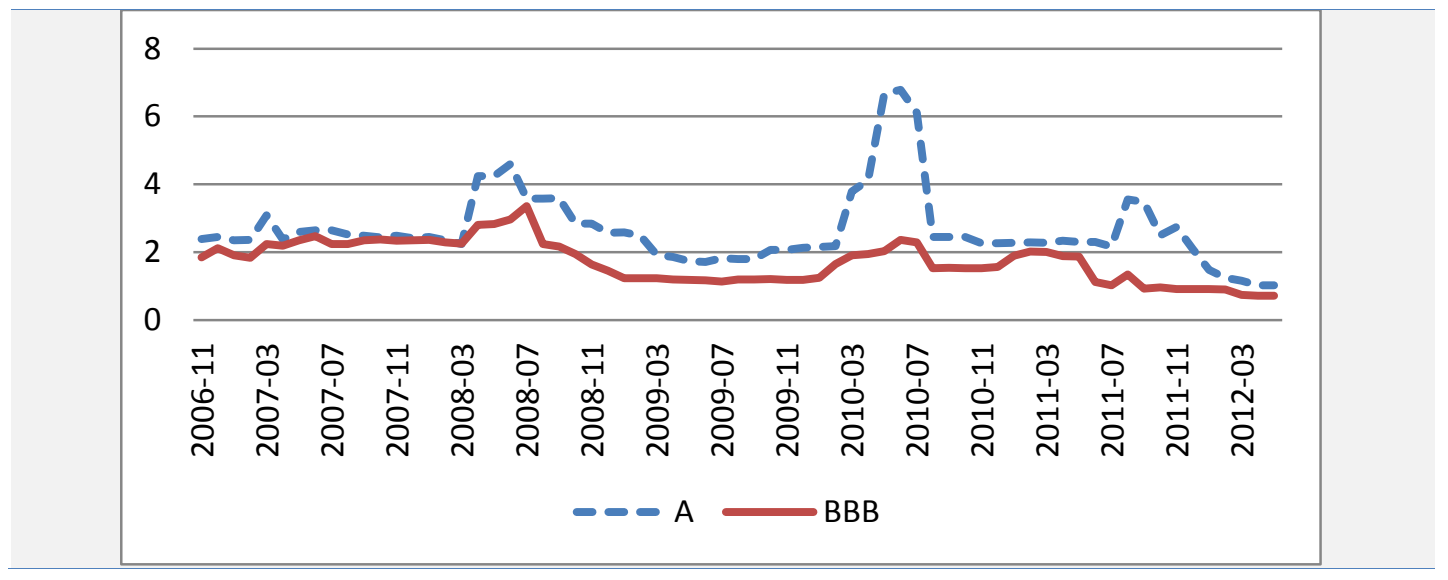

The distance-to-default values were calculated from monthly stock prices and their monthly volatility levels between November 2006 and April 2012. Figure 02 shows that the two values of distance-to-default from both samples move together creating similar paths as they face default. The values of distance-to-default of defaulted banks actually move toward zero which signifies a warning of default. Some of the other samples that went through bankruptcy actually showed negative values of $d_{2}$ as they move toward default time.

Another comparison between the distance-to-default values of survived and defaulted banks with ratings ${ }^{17}$ of $\mathrm{AA}$ and A, respectively, shows clearer path difference for both banks as shown below. The focus is how the value of distance-to-default of default bank moves toward its actual default time.

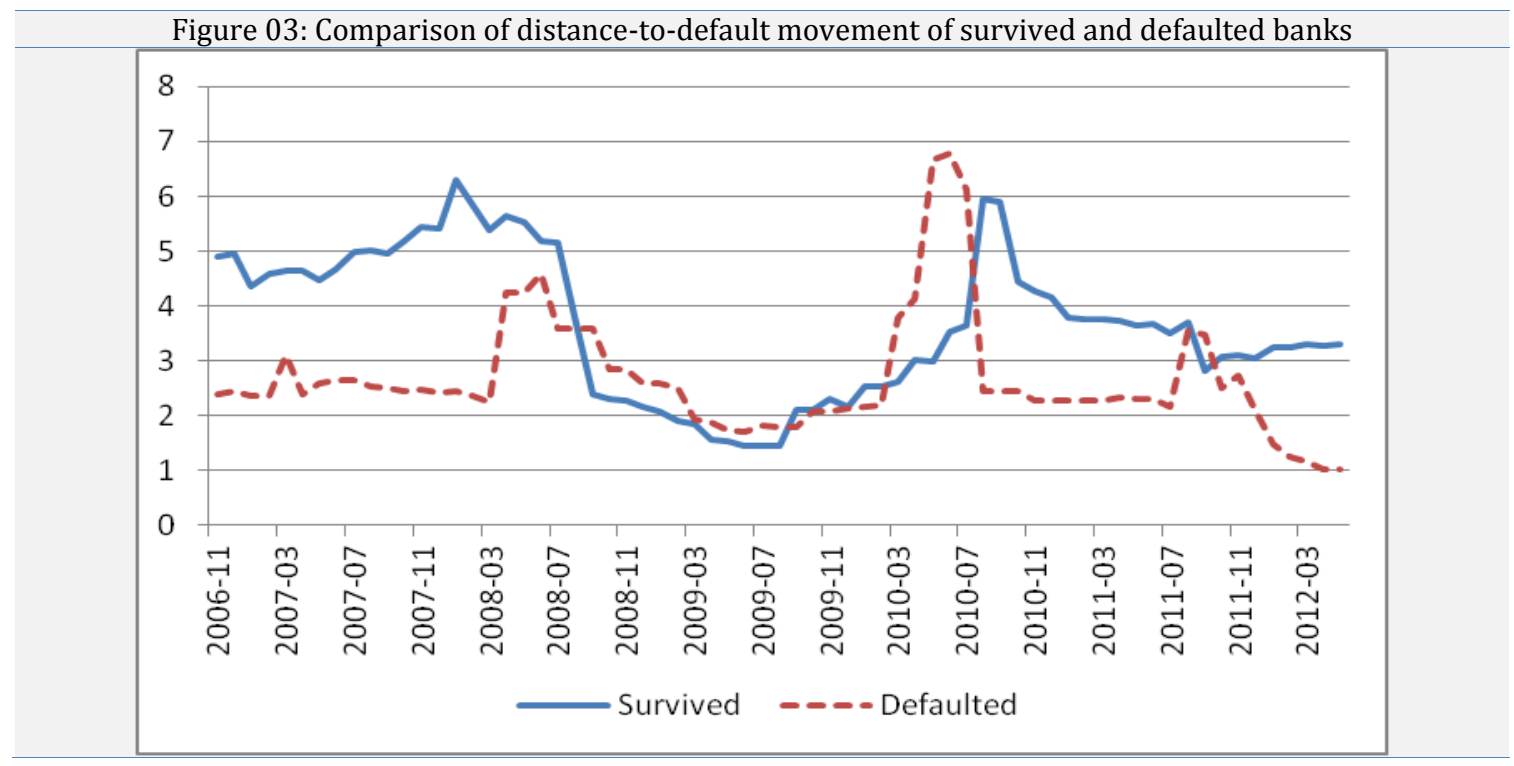

It is possible to see from the figure 03 that the distance-to-default value for the defaulted bank converges toward zero whereas the value of the survived bank maintains its level well above zero. Although the warning signal does not show graphically until the two lines start to diverge after mid-2011, figure 03 still provides the evident interpretation of how momentum of distance-to-default values matches default possibility. The low values between the end of year 2008 and the beginning of 2010 will be discussed later in this study. Also, the high peak around middle of year 2010 will be explained further with another sample.

\subsection{Distance to default movement of survived banks}

None of the listed banks from year 2000 still are listed as of today. This is because all existing banks either defaulted, were acquired by other banks or were delisted then listed again as a holding group. Survived banks here, then, means mostly delisted banks that are now listed again as holding companies. This study focuses on the values of distance-to-default of those survived banks up until their business events took place. The core target of the empirical test is to show that the obtained values maintain the validity of default probability calculation model. This would mean that the values should stay well above the zero (default point) or should not show any negative numbers. 
Samples were selected based on the longevity of the survived banks mainly because short time of period may not visually reveal the movement of distance-to-default value. All of the selected banks have the ratings of either AAA or AA as of their last listed month in the South Korea equity market. First, we examine the movement of distance-todefault values of sampled banks years between 2004 and 2008.

The key implication of figure 04 is that despite the distance-to-default values of sample banks do not always move toward the same direction during certain given time periods, they all maintain distant from the default point to a certain extent and if data from JB and BS are excluded from the figure, it would look as figure 05.

Figure 04: Distance-to-default movement of survived banks (before September 2008)

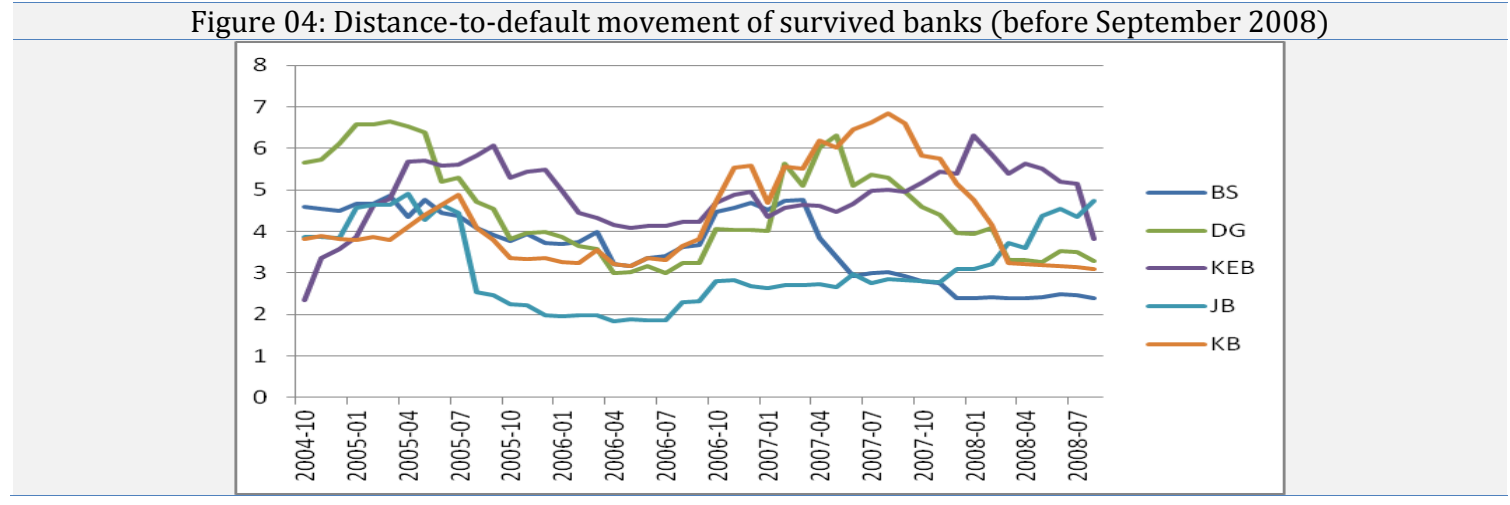

Figure 05: Distance-to-default movement of survived banks (before September 2008)

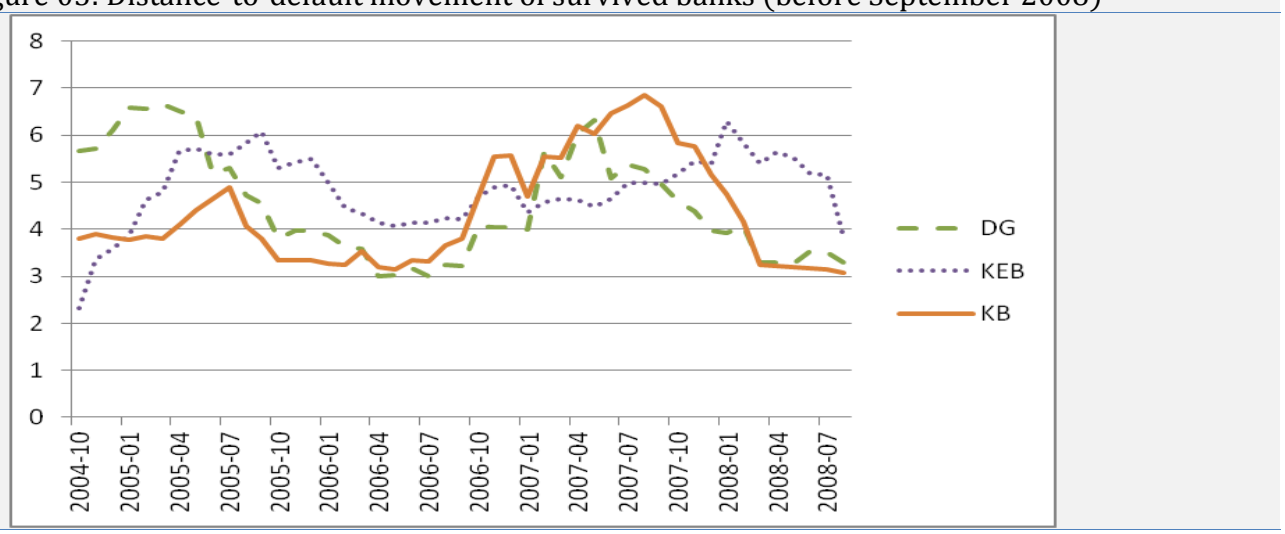

Now, we see clearly that values of all three banks move relatively together along the time period. All move downward in the early years and after hitting the trough around early-2006, all move upward again. Then, all move downward again as they enter global financial distress in 2008. This finding signifies that the distance-to-default values of most survived banks conform in terms of their movement. The direction of $d_{2}$ movement matters (whether the values converge or diverge one another) when determining the default signal as shown in the figure 03.

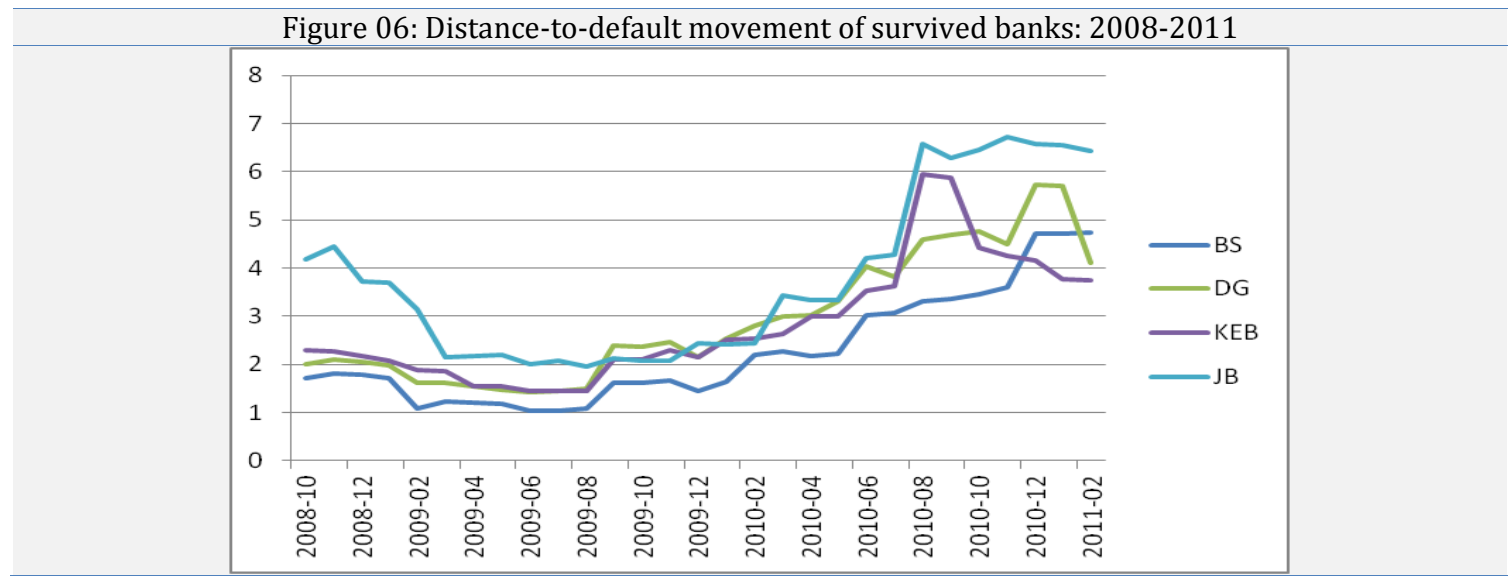

This time we will examine the same sample values observed between 2008 and 2011. Since KB was delisted and listed again as KB Financial Group in the year of 2008, only the rest 4 out of 5 banks will be tested starting 2008 until 2011 for data consistency purpose. 
The values of distance-to-default of the sampled 4 survived banks all move toward the same direction within tolerable range and the levels of the obtained values again are consistently placed well above their default point which is at distance-to-default equals zero. Unlike the previously discussed distance-to-default values for the default banks, the survived banks showed their calculated values that have no considerable signs or warnings of default. Much emphasis is on the two critical characteristics in order to visually foresee the upcoming default event: (1) whether the movement of observed distance-to-default value is in line with its peer group; (2) Whether the observed distance-to-default value is actually "distant" from zero's. In this case, the observed values of all 4 survived banks hold the above mentioned two conditions and, therefore, presumably we find no particular reason to expect default event.

\section{04 Reflection of historical and economic impact}

Now this study will further consider and discuss whether the calculated value of distance-to-default actually reflects the external effect such as economic recession or any internal business event. Default may incur due to a firm's specific capital structure but in most cases, external economic impact indirectly first affects a firm's business environment and then the following poor performance of a firm leads to eventual default. It is also important to check that our calculated values deliver the warning signals of the external impacts.

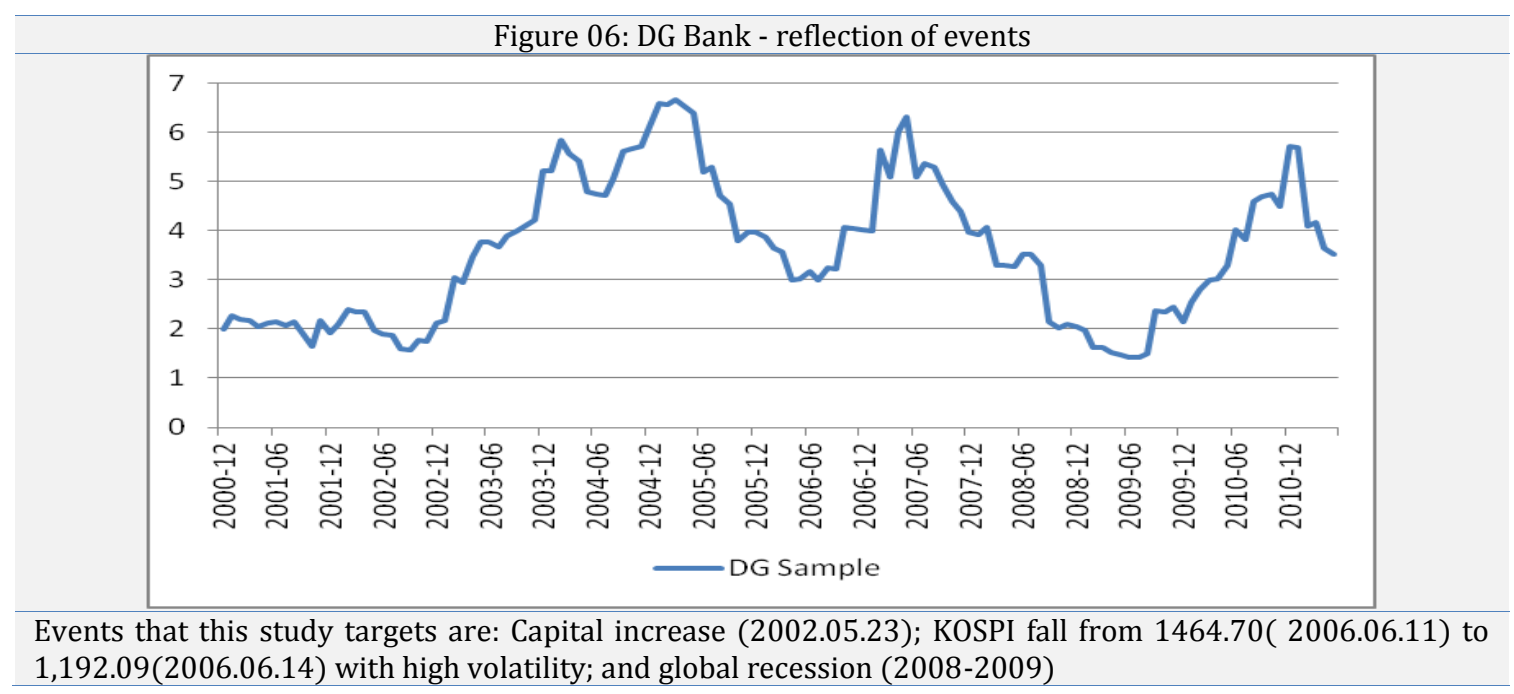

From the given samples, the longest listed bank is selected to explain whether EDF model holds its validity by cross matching the movement of distance-to-default value with any significant internal and external event occurred at a certain given time. The whole view of the distance-to-default value between year 2000 and 2010 is shown in the figure 07 .

In this study, we take one internal effect and two external economic events. The first effect is capital increase. The capital injection of KRW 6.6 billion clearly shows on figure 07 that the distance-to-default value drastically surges in year 2002. Our observed values well reflect the positive effect to the bank's capital structure. Secondly, the drastic fall of KOSPI index level and the increase of relatively high equity volatility ${ }^{19}$ of DG bank are well reflected and captured in the figure. Market sentiment often plays a great role that investors seldom sensitively react to future prospect of not only a specific firm but also of overall economy condition. Regardless of a firm's current performance, market expectation on both local and global economy may influence the price of the firm's equity price and the value of distance-to-default. The last impact is the global breakdown and financial recession in 2009 which also could be inferred from the figure where the value of distance-to-default moves deep downward. Although, the inferred value of distance-to-default is determined as a combination of individual performance and economic situation, it is fair to assert that the above findings deliver a fairly accurate glimpse of both internal and external impact.

\subsection{EDF model evaluation}

The EDF model showed its powerful results in assessing credit default risk of banks that the early warning signs of default could be captured by taking account of the movement and momentum of the distance-to-default values

\footnotetext{
${ }^{18}$ In fact, zero does not signify the default point. Zero only means high default probability. In standard normal distribution zero distance-todefault will give you $50 \%$ chance of default. (e.g. 1\% default probability if the distance-to-default value is 2.33.)

${ }^{19}$ Equity volatility of April, May, June and July in 2006 were $10.44 \%, 10.31 \%, 9.91 \%$ and $10.44 \%$, respectively where equity volatility of the past year with was $4.61 \%, 4.71 \%, 5.83 \%$ and $5.76 \%$.
} 
compared within the peer group. Although the exact default probability of each bank was not calculated and the absolute default probability level was not deliberately found, the movement trend of distance-to-default itself revealed its significance and contribution to the finding of passage of default risk. Moody's Analytics in their paper ${ }^{20}$ published in 2010 stated similar problems incurred from high or low absolute EDF values. Moody's Analytics suggests to focus on the relative EDF values within its peer group and its direction of EDF values in assessing financial institutions, and the high or low EDF values come from different levels of the capital structure ${ }^{21}$. Despite of the concerns of EDF model for financial institutions, the model still holds its validity in applying to banks in South Korea.

\subsection{Application}

At this point, we have discussed the validity of EDF model in applying to financial institutions and will further investigate how the EDF model can be applied other than its direct application to credit risk management. In the Over-The-Counter (OTC) derivatives market, especially banks, participants are exposed to credit risk from counterparties. Unlike markets with a clearing house, any transaction in the OTC market cannot be protected from credit event and consequently prior to all inter-bank transaction, the participating financial institutions require bilateral legal agreement and they seldom mutually request for credit support of collaterals according to the exposure levels. The legal agreement is called ISDA agreement ${ }^{22}$ and the credit support agreement is called Credit Support Annex ${ }^{23}$. Size of posting collateral from negative Mark-to-Market side to the opposite institution grows rapidly due to various OTC derivatives trades and the following large amount of credit support as collateral starts to become a burden to many collateral provider. Minimizing credit risk until all transactions become risk free is not an affordable solution. Collateral management which maintains certain profitability with lowest possible risk is rather preferred and desired.

\subsection{Collateral management}

Under the agreement of CSA, both sides of transactions require to provide eligible collateral from the negative mark to market side to the opposite side of the transaction in order to mitigate credit risk in unsecured financial transactions. For instance, at a certain time, suppose bank A and bank B have a number of FX swap, CRS or IRS outstanding contracts and both banks would have a mark to market exposure due to the price changes of underlying products. One will have a positive mark to market exposure and the other will have a negative mark to market exposure (also both sides of the exposure could be even but it is highly unlike). The bank with a positive mark to market exposure will claim the counterparty to deliver collateral amount equal to the exposure that exceeds the level of thresholds.

[Required Collateral Amount $]=[$ Total Exposure $]-[$ Corresponding Threshold Amount $]$

\subsection{Problems with threshold}

The existence of threshold makes convenient to both parties because repetitive small amount of collateral movement costs more than mitigating counterparty's credit risk. However, setting the threshold levels between the two contractual parties is an often raised problem. The global standard is a bilateral agreement to set the maximum and minimum threshold level that accordingly match each level of ratings provided by global credit ratings agencies such as Moody's, S\&P or Fitch. For example, a financial institution with its credit rating of AAA may have a threshold level of USD 40 million. This means that the institution does not have an obligation to provide any collateral to its counterparty as long as its exposure does not exceed negative USD 40 million. If the mark to market exposure becomes negative USD 50 million then the institution must deliver collateral amount of USD 10 million to the counterparty. Also if the credit rating of the financial institution falls to AA, different level of threshold could be applied depending on the agreement. All listed South Korean banks currently show only two ratings that are either AA or AAA from local rating agencies ${ }^{24}$ and globally $\mathrm{A}$ or $\mathrm{Aa}^{25}$. Obviously all South Korean banks with the same ratings do not possess the same or close to the same credit risk level. Among those whose ratings are AAA from the local rating view, some of the banks will have higher intrinsic credit risk than other banks and these banks are confronted to deliver more than a fair collateral level because the threshold is fixed to follow the corresponding

\footnotetext{
${ }^{20}$ Munves, D., Smith, A., Hamilton, D., 2010, Banks and their EDF Measures Now and Through the Credit Crisis: Too High, Too Low, or Just About Right?

${ }^{21}$ Liabilities of financial institution often range from senior obligations to hybrid capital such as preferred shares which rank just above equity.

22 The ISDA Master Agreement is a development of the Swaps Code, introduced by ISDA in 1985. It is commonly used for OTC derivatives transactions internationally.

${ }^{23} \mathrm{CSA}$ is a legal document which regulates collateral for derivatives transactions.

${ }^{24} \mathrm{KIS}$ and NICE rating

${ }^{25}$ Moody's rating
} 
ratings. Table 4.1 shows debt ratings of listed banks (or holding group company) as of the first quarter of 2014. In this case, threshold level

\begin{tabular}{lcc}
\hline & Table 02: Credit ratings - South Korea listed banks as of 2014 1Q & \\
\hline Name & Moody's LT & KIS/NICE LT \\
\hline Cheju Bank LTD & A3 & AA+ \\
Woori Finance Holdings Co Ltd & A2 & AAA \\
Woori Bank & A1 A \\
DGB Financial Group Inc & & AAA \\
Daegu Bank & A2 & AAA \\
Industrial Bank of Korea & Aa3 & AAA \\
KB Financial Group & & AAA \\
Kookmin Bank & A1 & AAA \\
Hana Financial Group Inc & & AAA \\
Hana Bank & A1 & AAA \\
Korea Exchange Bank & A1 & AAA \\
JB Financial Group Co Ltd & & AA+ \\
Jeonbuk Bank & & AA+ \\
BS Financial Group Inc & A2 & AAA \\
Busan Bank & A2 & AAA \\
Shinhan Financial Group Co Ltd & & AAA \\
Shinhan Bank & A1 & AAA \\
\hline
\end{tabular}

\subsection{Suggestions}

We further elaborate the current collateral threshold method with "smoother" threshold level from the collateral management stand point by using our distance-to-default values. Universally eligible collateral is always cash, especially hard currencies such as USD or EUR, and financial institutions often utilize cash collateral because cash transfer is quick and convenient to manage. According to ISDA Margin Survey in 2010, 82 percent of collateral used was cash. The main problem with cash collateral we focus is that the return benefit of collateral provider from cash collateral is minimal, meaning the receivable USD cash interest is calculated with effective federal fund rate, and EUR cash interest is calculated with EONIA rate ${ }^{26}$. Both rates would be significantly below the funding rates of all financial institution. Provision of large amount of collateral could then lead to liquidity risk as well. Hence, we suggest a way to minimize loss from posted cash collateral without taking additional credit risk.

\subsubsection{Threshold smoothing}

The focal idea is that the distance-to-default is calculated from market value of equity and its volatility. Both variables can be directly retrieved from the market data and thus regardless of who calculates the value of distanceto-default, all should agree to a specific value with bearable difference and will hardly encounter large discrepancy. By smoothing threshold level, required collateral amount will be in accordance with a firm's credit quality. The detailed method is as follows.

The adequate collateral amount is determined by deducting upper threshold amount from the total exposure and then adding the difference of upper threshold and lower threshold multiplied with an arbitrary number, K, of scaled between zero and one. Upper threshold implies a step higher threshold level of a firm's credit rating. (for instance, if USD 40 million threshold level at credit rating " $A$ " and USD 50 million threshold level at credit rating "AA" are applied then a firm with its credit rating "A" has an upper threshold is USD 50 million and lower threshold is USD 40 million.) The value, $\mathrm{K}$, is the smoothing factor which is determined by the distance-to-default value.

$\left[\begin{array}{c}\text { Collateral } \\ \text { Amount }\end{array}\right]=\left[\begin{array}{c}\text { Total } \\ \text { Exposure }\end{array}\right]-\left[\begin{array}{c}\text { Upper } \\ \text { Threshold }\end{array}\right]$ $+\mathrm{K} \times[$ Upper Threshold - Lower Threshold $]$

Where,

[Upper Threshold] $>$ [Lower Threshold]

Upper threshold means higher credit with higher threshold level such that

$\mathrm{K}=1-\frac{(\mathrm{DD}-\mathrm{Min})}{(\operatorname{Max}-\mathrm{Min})} \quad$ if Min $<\mathrm{DD}<\operatorname{Max}$

${ }^{26}$ Federal Fund Rate: 0.06 0.1, EONIA: 0.15 0.25 

$\mathrm{K}=0$
if $\operatorname{Max}<\mathrm{DD}$
$\mathrm{K}=1$
if $\mathrm{DD}<\mathrm{Min}$

Min, minimum value of DD, and Max, maximum value of DD, are decided between the contractual parties.

For example, a bank with A rating(corresponding threshold is USD 1 million) is placed just below AA rating(corresponding threshold is USD 2 million) and the current total exposure is USD 3 million. The distance-todefault value is found to be 8 , and the maximum and minimum DD values mutually agreed between the two parties are 5 and 10, respectively. Then the smoothened threshold is calculated as shown below.

$\begin{aligned} {\left[\begin{array}{c}\text { Collateral } \\ \text { Amount }\end{array}\right] } & =[\mathrm{USD} 3 \mathrm{M}]-[\mathrm{USD} 2 \mathrm{M}]+0.4 \times[\text { USD } 2 \mathrm{M}-\text { USD } 1 \mathrm{M}] \\ & =\operatorname{USD}[3 \mathrm{M}-2 \mathrm{M}+0.4 \mathrm{M}]=\operatorname{USD} 1.4 \mathrm{M}\end{aligned}$

$\mathrm{K}=1-\frac{(8-5)}{(10-5)}=0.4 \quad$ if Min $<$ DD $<$ Max

Without smooth threshold, the bank from the example requires to deliver USD 2 million worth collateral to the pledgee whereas the bank only requires delivering USD 1.4 million after smoothing its threshold. The benefit of the bank is the opportunity cost of USD 0.6 million.

$\left[\begin{array}{c}\text { Opportunity } \\ \text { Cost }\end{array}\right]=\left[\begin{array}{c}\text { Funding } \\ \text { Cost }\end{array}\right]-\left[\begin{array}{c}\text { Overnight } \\ \text { Cost }\end{array}\right]$

Overnight Cost: Federal Fund Rate, EONIA Rate, Overnight Call Rate and etc.

\subsubsection{Actual practice}

Total of 24 brokerage firms are currently listed in the stock market in South Korea as of the first quarter of 2014 and 4 samples of brokerage firms with their long term and unsecured debt capital with "AA" ratings are sampled to apply the "smooth" threshold level.

All 4 firms have similar ratings of which 3 are rated AA+ and one is rated AA-27. In 2010, all 4 firms have similar level of distance-to-default values and the values move along together until 2013 then all start to conspicuously diverge. Despite of their ratings in 2014, clear difference between distance-to-default values of the SSS and MRA can be vividly witnessed in the figure 4.1 .

The distance-to-default values for the last month of test period, February 2014, and the K value(with max 8 and min 3) from equation 4.2 are shown in table 4.2 . The idea is that although the 4 sample firms have the same ratings of AA, levels of their credit risk differ much. However, by calculating previously introduced K-value of each firm, the threshold level can be smoothened individually and credit risk of each firm will be reflected into the threshold level.

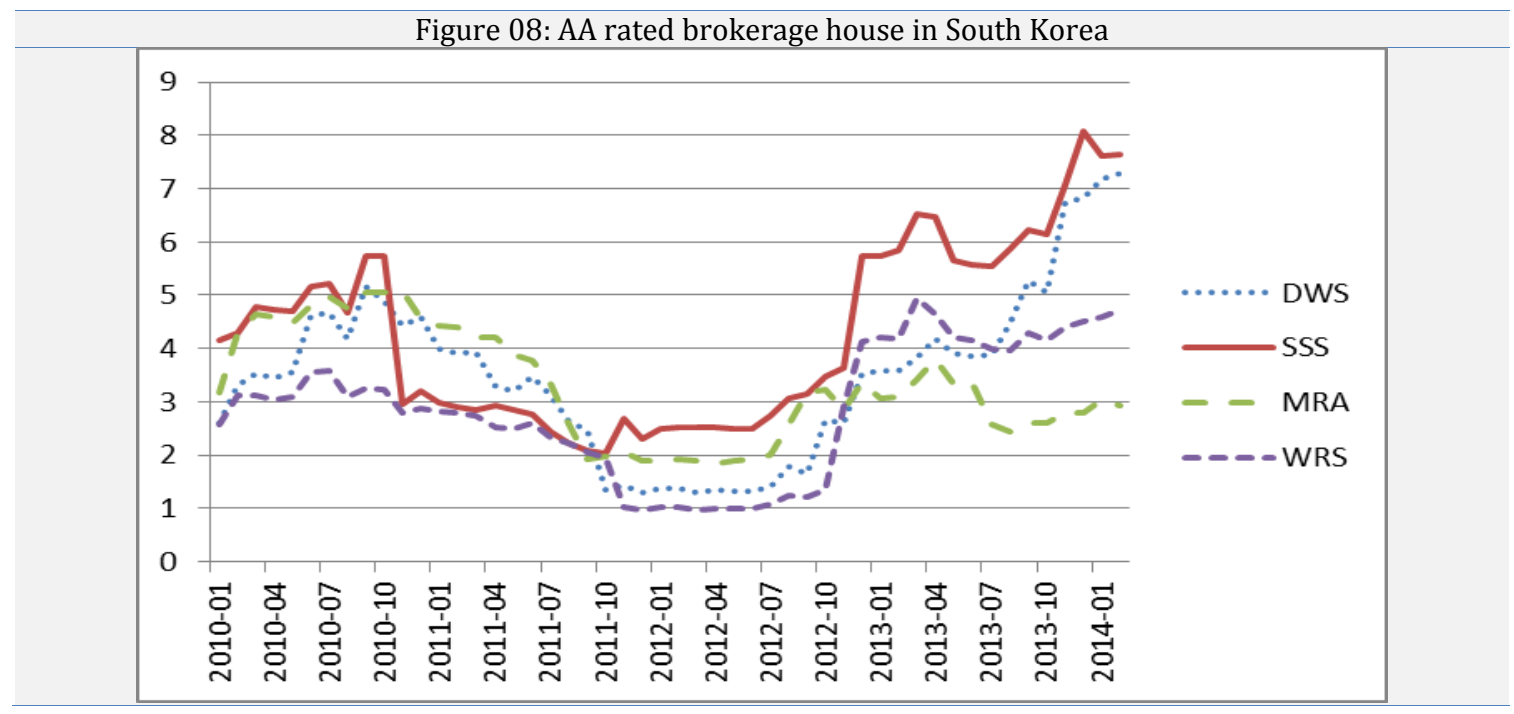

27 Threshold level does not specify ratings with plus or minus. 
Depending on the exposure status, the pledger can become a pledgee within the contractual period as number of transactions increases. This smoothing method will always reflect counterparty default risk as well as help allocate resources efficiently by reducing idle cash provision as a form of collateral.

\begin{tabular}{lllll}
\hline \multicolumn{4}{c}{ Table 03: Distance-to-default and K-values for brokerage firms } \\
\hline & DWS & SSS & MRA & WRS \\
\hline Credit Ratings & AA+ & AA+ & AA- & AA+ \\
DD $\left(d_{2}\right)$ & 7.297 & 7.6417 & 2.9405 & 4.7312 \\
2014.2 & 0.1405 & 0.0717 & 1 & 0.6538 \\
K-value $^{28}$ & & & & \\
\hline
\end{tabular}

\subsection{Summary and discussion}

\subsection{EDF performance}

In conclusion, the EDF model performed well enough for financial institutions, especially for banks, acting as an early warning signal of default event and subsequently can be easily applied to collateral management for financial institutions in the OTC market.

Many previous studies showed the validity of EDF model but most of the studies end their findings with testing the model empirically utilizing market observed data. Also, not many papers have dealt with credit risk of financial institutions since in most cases, financial institutions are the ones who need credit risk protection. The application of the EDF model is limited to a certain field of study (e.g. credit risk or default risk related area) but in the actual work environment, many firms and financial institutions, of course, encounter increasing needs to manage counterparty credit risk. Stock market participants, credit risk managers, loan reviewers and more people adopt the model because of the forward looking property of the model and its simplicity.

This study has delivered ideas that the credit risk model, EDF model, is correctly functioning for South Korean banks and it can be applied in collateral management by providing adequate level of collateral according to the level of default risk. We expect our "smooth" threshold level can contribute to enhancement of resource allocation efficiency for participants in the OTC market.

\subsection{Discussion on our findings}

Global financial policies and reform movements emphasize market stability, and upcoming US and EU regulations may act against OTC market expansion. We expect risk management will become a core issue to all financial institutions. Collateral management for OTC market participants, hence, could become exceedingly important which eventually controls trading activity. In the midst of current atmosphere, we seek for efficiency in use of collateral. We intend to point out that the excess collateral provision between financial institutions may lead to less profitability for all participants. Further, we suggest the bilateral credit support agreement to include a certain level of threshold in accordance with each credit rating to avoid unprofitable daily transactions, and create linear and fine-tuned threshold level to prevent excess or shortage collateral provision.

\subsection{Limitations}

The critical weakness of EDF model would be that if a firm or, in this study, a bank is not listed in the exchange market the data cannot be retrieved at all. In this case, CDS spread or bond spread implied distance-to-default could be the substitute values but both spreads are not directly observable in the market.

The use of normal distribution throughout the whole study may underestimate credit risk because the actual historical default distribution is known to have fatter tail. The asset value and its volatility are inferred from equity market value and its volatility observed from the exchange market. Equity value not only varies with the firm's intrinsic risk and performance but also with the external impact and moreover non-market impact could also affect the variables due to the inefficiency of secondary equity market. In addition, small trade volumes of a specific firm in the market could also mislead the equity value and volatility.

\footnotetext{
$\begin{aligned}{ }^{28} \mathrm{~K} & =1-\frac{(\mathrm{DD}-\mathrm{Min})}{(\text { Max-Min })} & & \text { if Min }<\text { DD }<\text { Max } \\ \mathrm{K} & =1 & & \text { if DD }<\text { Min }\end{aligned}$
} 
Market convention is extremely difficult to ignore. For example, swap dealers still use Yahoo! Messenger to execute trades and each product dealer has market price quote convention as well. Suggesting a new methodology to change the existing standardized contract will be somewhat difficult. The biggest challenge for implementing our findings in OTC market is the latest market trend in which financial institutions prefer cash collateral only with zero threshold level to avoid all possible credit risk regardless of the accompanied cost.

\section{References}

Bharath, S., Shumway, T., 2004. Forecasting default with the KMV-Merton model, AFA 2006 Boston Meetings Paper, University of Michigan.

Black, F., Scholes, M., 1973. The pricing of options and corporate liabilities. The Journal of Political Economy, 81: 637-659. http://dx.doi.org/10.1086/260062

Caouette, J., Altman, E., Narayanan, P., Nimmo, R., 2008. Managing credit risk: The great challenge for the global financial markets, John Wiley \& Sons. http://dx.doi.org/10.1002/9781118266236

Chan-Lau, J., Jobert, A., Kong, J., 2004. An 0ption-based approach to bank vulnerabilities in emerging markets, Epub No. 04-33. International Monetary Fund.

Crosbie, P., Bohn, J., 2003. Modeling default risk, Research Paper, Moody's KMV.

Hull, J., 2002. Options, futures, and other derivatives, Prentice Hall.

Hull, J., Predescu, M., White, A., 2004. The relationship between credit default swap spreads, bond yields and credit rating announcements, Journal of Banking and Finance, 28(11), 2789-2811. http://dx.doi.org/10.1016/j.jbankfin.2004.06.010

Jo, H., 2003. Credit Risk: Measurement and management, Segyeong.

Merton, R., 1974. On the pricing of corporate debt: the risk structure of interest rates, Journal of Finance, 29(2), 449-470. http://dx.doi.org/10.1111/j.1540-6261.1974.tb03058.x, http://dx.doi.org/10.2307/2978814

Munves, D., Smith, A., Hamilton, D., 2010. Banks and their EDF measures now and through the credit crisis: too high, too low, or just about right?, Research Paper, Moody's Analytics.

Vassalou, M., Xing, Y., 2004. Default risk in equity returns, Journal of Finance, 59(2), 831-868. http://dx.doi.org/10.1111/j.1540-6261.2004.00650.x 